DOI: https://doi.org/10.24144/2409-6857.2018.1(51).23-27

UDC 33-2964

\author{
Ambrozy M.
}

\title{
SELECTED ISSUES OF CAUSALITY IN ECONOMICS
}

\begin{abstract}
In the article, the author tries to clarify selected aspects of causality in the economy. Although sometimes causality in the economy is not obvious, we think it is necessary. We strive to address the phenomenon of causality in terms of science methodology. We also deal with causality and mathematical modeling in the economy. We also perceive certain common features of causality in the natural sciences, especially in physics and economics. The principle of causality on a similar basis is also applicable in the economy. We believe that the denial of causality in the economy is scientifically incorrect. We are attempting to argue indirectly in a dispute where we state what would happen if it did not pay the principle of causality in the economy. Hume's arguments against causality in the economy are not convincing. The statistical nature of the economy in no way deflects the causal principle, as it is not in statistical physics. Explains without the principle of causality would in many cases be impossible in economic terms.
\end{abstract}

Keywords: Causality, Theoretical Economics, Cause, Methodology of Science

Introduction. The problem of causality in economics in the area of Slovakia and Czech is dealt with by the lot of authors: Korda, Lubelcová, Dobeš etc. In the world, it is worth mentioning C. Granger, who proposed application of non-deterministic causality in economics [11]. Prior to Granger's appearance, the well-known economist Samuelson was addressing the issue [9].

Literature review. The computations of authors who deal with problems at a general level are not short: Masih, Zellner, Joerding, Hicks, Brock, Pearl, Hoover, Dopfer, Barrow and Rouse and many others.

Article purpose. Causality in science and philosophy is understood in different ways, therefore, first of all, it is necessary to define terminologically the semantic and denotative aspects of the concept. We consider this necessary for the further use of this term in our study.

Presentation of the main research data. For the first time in the European context, the system of causality can be said in connection with Aristotle. As is known, Aristotle distinguished four causes: matter, form, action and purpose. Scholasticism and neo-scholasticism did not add to the understanding of the cause of anything substantial, even in the case of John of St. Tomas who also dealt with this issue. In the new context, the term reasoning is discussed by David Hume. Philosopher has a notion of causality, he considers it unavoidable to make a statement between cause and effect. From the observation of the sequence of processes that unfold one after another, one can not judge the category of

(C) Ambrozy, Marián Marianovich, PhDr. PhD., ViceRector for Science, Research and International Relationship, International Business School of ISM Slovakia in Prešov, email: ambrozy@ismpo.sk cause and effect. Hume in this statement, in essence, destroys the definitions of cause and effect. With criticism of the concept of cause, the early Russell. In modern times, there are two main approaches to the treatment of causality in philosophy. The first the classical Aristotelian - considers the relationship between cause and effect in terms of energy transfer, or force. Another approach, inspired by positivism, treats causality as a certain sequence, expressing the relationship between two isolated facts.

In the social sciences, the applied definition of causality is that we justify the occurrence of one event by the action of another event. In general, without the concept of causality in science, it is difficult to manage. However, we are not happy with Hume's stating the doubt of causality in science, because this is a fundamental negation of causality. One can dispute a special case: if events follow one another, then the previous event should not be the cause of the next one, but this, of course, will prove to be not the best solution in science, a priori destroying the concept of causality.

The counterfactual theory of causality was formulated by David Lewis in 1973. It got its name from the analysis of causality through counterfacts. The counterfact is an assertion of the form "If A, then $\mathrm{B}$ " and, accordingly, "If $\mathrm{A}$, then B". The difference in material terms, however, is significant: it points to those things that are contrary to facts. In short, incredible terms are used in the composite sentence. Lewis argues that in the analysis of causality, we can refer to counterfacts. Related to this and the question of possible worlds. In the logic and semantics of possible worlds, Lewis's "preservation of the center of gravity" dominates. Lewis positions himself as a posibilist. The difference between the real and possible worlds can be such that in this "real" world we find ourselves as 
observers. The radical original version of Lewis's posibilism, which rejects surrogate modal realism, suggests the existence of many equally real possible worlds. The individual at the same time is associated with only one of the possible worlds, which, in turn, are separate and have their own causality. The causal-ontological approach denies certain concepts of the philosophers of physics. It is an unambiguous and precise definition of cause and effect. In the case of the regularity expressed by mathematical equations, one should speak of a non-causal law. „Mathematician Grete Hermann in an article entitled Die naturphilosophischen Grundlagen der Quantenmechanik from 1935 offers its own philosophical interpretation of the causality issue and distinguishes it from predictability, which can be perceived as the age and tradition added additional determination, non-existent from the concept of causality“ $[8,560]$.

It is necessary to distinguish between scientific knowledge of the world, the life of the human community and the field of economics. The roots of cognition in the first area go back to the causal ontology, where the contradictoriness of reality (falsification) represents a certain knowledge (which does not correspond to reality). If a contradiction is not revealed, everyone has the right to consider these statements as a basis for further development of assumptions. Any willful deviation from this direction should be considered unscientific.

In this context, Internet and communication and public relations also play an essential role in today's turbulent times. Author Hvizdova et al. (2017) says that "by correctly setting up public relations in the Internet environment and constantly analyzing its effectiveness, the company's management can satisfy the needs of customers and achieve the desired economic results" [13]. In the field of economy, everything is much more complicated. Here everything depends on the free will of man. Therefore, it is first necessary to assess the significance of human life in the evolution of all that exists. What we can learn from our knowledge is certain ethical rules that are designed to keep people in the direction of that high goal. Given this position, human life must be recognized for almost sacred, which we have already tried to show in previous discussions. The human mind has no way to comprehend reality, when the evolution (and all life) of everyone starts from one cell. Human arrogance acts only negatively, which, most likely, more than once will manifest itself in the future. Mokrišová [7, 26] states that ,today's world is based on the principle of information, the primary objective of which is to obtain important information as the first and then to benefit from this“".
Therefore, it is necessary to thoroughly consider what causality in the economy means. Causality can only be associated with individual events. It is impossible to combine it with statistical estimates. In specific circumstances, many different factors come into force that can not be taken into account, since they relate to a specific individual. The management system can not remain constant, it must take into account the situation that is changing in development. In the theoretical economy, the voices of those who are hostile to the use of the causal-ontological principle in explaining economic phenomena begin to sound. Such prejudice will have consequences contradicting empirical evidence. The theoreticians of the economy treat ambiguity with regard to the problem of causality. In general, most economists advocate the principle of causality in theoretical economic thought. A specific situation occurs with anomie. It is a specific state of society in which more or less cease to apply social norms and laws [5, 36] It may resemble a situation that is analyzed by Maldiney's incident Pavol Sucharek [12].

A real problem can arise with aggregated variables. Nevertheless, economists can explain these variables without any serious discrepancies in accordance with the principle of causality. The economy is looking for solutions based on models with representative agents. Individual units are also determined with respect to aggregates, in this case the cause can be guessed. The next problem may be a large number of estimated and, accordingly, significant conditions that can actually manifest themselves, and this makes it difficult to determine the cause already at the theoretical level. In the natural sciences it is easier to discover the cause, in the economy it is possible to neglect causality, which has a temporary conditioning. As applied to the economy it is possible to accept only his criticism of the erroneous judgment post hoc, ergo propter hoc. To this responds from the standpoint of the methodology of science $\mathrm{H}$. Poincare. On the other hand, while Hume stressed the asymmetry of the possibility of discovering cause and effect, in the sense of its one-pointedness, the economy allows symmetry in this case: the cause can in fact be a result simultaneously. If the investigation comes instantaneously, we are talking about a simultaneous causality, which contradicts Hume's assertion that the cause is the cause of the result. In the economy, meanwhile, it often appears that the reason must be long-term to produce a result, if the price of oil is to grow in the short term, nothing will happen, but in the long run it will cause the growth of many prices. Sustainable, responsible financial investment or positive-influence investing has its cause in ethical value investing. Many investors are asking for 
support, appreciation and visibility of business entities at home and abroad [ 10, 197]. Another problem in the economy is the interdependence of the quantities. The problem is related to the relationship of interdependence and causality.

Although causal explanations in economics are used quite often, it remains relevant fact that economic theories contradict each other, many interpretations of the causes of events are often stated quite the opposite. Hence the dispute about the specific provisions of economic theory between individual schools and, consequently, the dispute about the search for reasons. Neglect of the influence of an unknown cause is also possible in the economy, as pointed out by the above-mentioned H. Poincare. Economic statistics demonstrate common features in the field of problems of causality with the statistical division of physics. A key role here is played by probability theory, as already indicated by Granger's causality tests. In these tests, it is determined which connection exists between the variables in question. If we add the history of $\mathrm{X}$ and $\mathrm{Y}$ to the variable $\mathrm{X}$ within the limits of the action on $\mathrm{Y}$, then it is easier to explain the relationship between $\mathrm{X}$ and $\mathrm{Y}$ within the probability, then the causal relationship will be actual until $X$ acts, which increases the probability of detecting Y.

„The central problem of the philosophy of science, according to Popper, is the problem of demarcation" [4, 28]. Even if the economy belongs to the social sciences, it is impossible to explain the phenomenon on the basis of the Durkheim sociological-ideological positions, according to which a social phenomenon can only be explained through another social phenomenon. John Roger Searle at the same time recognizes the importance of mental phenomena. Since the economy is not a social, but a humanitarian science, both of the stated positions would obviously be extreme. In their pure form, these points of view are even mutually exclusive. Already in the social sciences it is claimed, through psychology, and the economy contains a social segment.

"Social policy measures are efficiently integrated into the individualized life situations of people in order to help solve them. But also there can be applied vice versa conditional relationship, when the variable experience of adverse life situations of people is related to a wider social problem and this experience is generalized in it and then adequate social policy tools to address this issue are looked for" [3]. Many economic arguments require more logical analysis than observations, as, for example, in natural science. L. von Mises considers causality as a condition of activity. The position of this well-known representative of the Austrian economic school is based on Kant's ideas.
Von Mises considers economic laws to be based on the axiom of action and, in fact, not falsified, because they are a priori synthetic judgments. Economics, therefore, is understood as a kind of applied logic. It is known that Carnap considered a priori synthetic judgments to be meaningless, and Quine believes that instead of dividing judgments into a priori and a posteriori, a new division into necessary and contingent ones must be approved. Although von Mises notes that the economy is different from the empirical sciences, we must, in his words, recognize the timeless permanence with respect to the causes of the action, in order to know that they really exist. He also does not consider it possible to make full use of the prediction of causes, seeing the possibility of using it only as a historical method, that is, in the direction of the reverse chronological sequence of establishing the causes of events. We can say that von Mises considers the possibility of applying forecasting to the economy only as limited. In particular, he points out the meaninglessness of prognostic constants in the economy. Praxeology logically limits forecasting of economic events. The principle of causality is that, according to von Mises, is perceived as an understanding contained in our interpretation of action, as our influence, our intervention. Applicability of causality is established on the basis of a priori establishment, on the basis of teleology. This means that action, of course, presupposes a structure of reality that is regulated by the laws of causality, but the reality of the action itself does not have a causal structure. We can mention many concrete examples of documentation of causality in the economy, for example the business model as a strategic management tool [6]. Similarly, causality in the economy is used by Dimoschakis and Kouthouris to say: „further possible recession in the next years could affect negatively citizen's participation in physical and sport recreation activities“" $[2,2]$.

The mathematic model is preceded by a quantitative analysis. The condition for its construction is a thorough knowledge of a specific task and its main parameters. Conditio sine qua non is, obviously, a deep and concrete knowledge of the economy. The construction of mathematical models of the highest level is even more difficult. After compiling a mathematical model, it is required to find a suitable method as an algorithm for solving the problem. The methodological sequence of constructing a mathematical model consists of studying the modeled phenomenon and its economic description, from the mathematical formulation of the problem and constructing an algorithm for solving the model, and also from a qualitative analysis of the results and their economic 
interpretation. „The economists should consequently analyse new phenomena. They need to build new theories and disseminating them to wide community. New results in cognitive sciences and progressing ICT, advances in applied informatics and computational intelligence there are arising new opportunities for a dialogue with mental models and theories in the economic sciences" $[1,861]$.

Individual mathematical models based on the initial parameters (variable dependent or not) are divided on stochastic and non-stochastic. In stochastic models we are talking about an ambiguously determined dependence of parameters in the model, and the value of the quantities increases depending on the criterion of truth. The economic mathematical model should reflect the relations of economic phenomena and on the quantitative side. However, it is necessary to see behind it and its quality side.

Each mathematical model contains input conditions, exit conditions, and conversion conditions. The conditions of change are a process in which changes occur, for example, the transformation of resources into a product. When solving problems, it is necessary to remember the fact of the interchangeability of individual conditions, that is, that the result can be achieved through the use of alternative conditions.

It is important that in modeling it is also necessary to take into account the causal approach. Not being supporters of Laplacian determinism, nevertheless, we recognize the deterministic nature of economic processes. Certainly, only to a certain extent. On the other hand, the theory of games used in economics, which John Nash developed for this science, also makes sense, that is, the positive role of uncertainty and randomness should be taken into account. It is known that the identity of unstable physical systems from the topological point of view disappears even with small changes in the values, and it must be taken into account that real economic systems are much more complex than their conditional dynamic models. The projection of dynamic models, however, without a causal approach at all would be impossible. Moreover, along with the causal approach, one should keep in mind that Laplacian determinism in its strict understanding can not be applied in economic science, since it would be too simplistic to exclude both the physical and the economic phenomenon from the environment and it is also necessary to take into account the synergistic effect. About the pitfalls that accompany the generalization of the economic characteristics of an idealized individual, we have already said.

The mental models themselves, without any pretension to the connection with reality, also require the use of a causal approach, if they want to remain in the plane of possible Kripke worlds. Existing systems of elements that enter into economic relations also behave in accordance with the principles of causality. Such models, in turn, can successfully play the role of educational networks. Students can, directly within the framework of a virtual experiment, see how the situation in the economic model will change as long as several different parameters are interchanged. Computer modeling clearly shows the causal structure of possible worlds in terms of the possibility of building economic systems. The models in question should in no case be confused with attempts to display real samples.

Conclusions and prospects. We pointed to the clearly necessary existence of causality in the natural sciences, where, especially in physics, we can sometimes encounter views that attempt to disprove the causality in it. Such views only deny the essence of rationality in the natural sciences. Sometimes misunderstanding arises from the confusion of causality and predictability. Even if methodologically economics as a discipline differs from physics, the problems of causality have many similarities in them. Already Ludwig von Mises draws attention to the fact that, if the economy is not purely empirical science, causality does not go hand in hand with causality, but indicates that causality is a condition of processuality. Causality is defended by them mainly as an opportunity in reverse chronological order to determine the cause of the state. The problems of causality in phenomena of a statistical nature are essentially the same as similar problems in physics, therefore it is impossible to neglect causality in these sciences. On the other hand, the position of the economy reveals itself, according to which, the reason must act for a long time, that it should be indicative and bear the nature of the cause. The problem can create aggregated values or more conditions in determining the cause. Also, the real cause may be unobservable and hidden phenomena. Although the older historical school neglects causality in the economy, the causal structure of reality can not be refuted. At least some of the economic situations that make up a significant proportion of a multitude of economic phenomena can be attributed to causally conditioned phenomena, such as the accumulation of capital under economic growth, the long-term increase in the price of oil, and so on.

The problem of causality is connected with modeling. The problem can, from the position of causality, arise with a dynamic model containing a time factor, since such a model does not allow to simulate the reality from the point of view of the possibility of forecasting. For this reason, dynamic 
models are not a direct reflection of objective economic reality, but only simulated situations. Including, and therefore imitating a possible reality, follows in dynamic models, since real economic systems are subject to the principle of causality.

Discrediting causality not only in the natural sciences, but also in the economy is clearly pointless. Even the most complicated statistical situations in the economy can not exclude causality. Aggregate values, more conditions, and hidden variables are more of a scientific problem than an excuse for excluding causality from the economy. The accuracy of the economy is not violated in mathematical models, where causal relationships are simply a priori taken into account, while in realworld models, realistic situations must be simulated.

The article originated in the research role of project IG-KSV-01/2016-2.1.5 Ethics and social consequentions of separated problems of natural sciences.

\section{REFERENCES}

1. Andrášik, L. (2014). Using Softbots on Cultivation Economic Knowledge. Ekonomický časopis - Journal of Economics, 62 (08), 861-881 [in English].

2. Dimoschakis, S., \&Kouthouris, Ch. (2013) Hellas 2010-2011: Economic crisis and Quality of Life. Hellenic Journal of Sport \& Recreation Management, 10 (2), 1-19 [in English].

3. Hvizdová, E., \& B. Balogová (2016). Creative industry of selected handicrafts in Eastern Slovakia. Mainz: Logophon Verlag GmbH [in English].

4. Karaba, M. (2017). Revolutionary Theories of Scientific Progress. Warszawa, Rhetos [in English].

5. Lachytová, L., (2011). Social pathology. Prešov, VŠMP ISM [in English].

6. Mišúnová Hudáková, I., \& Mišún, J. (2013) Business model as a tool for strategic management on the example of a company Marvel entertainment. Economics and Management, 10 (2), 64-82 [in English].

7. Mokrišová, V. (2013). Marketing Information System. Fundamentals of marketing, 26-52 [in English].

8. Országh, L. (2013). Determinism, predictability, fatality and reductionism, or where is the place for free will? The Social Message of John Paul II. Ružomberok, Verbum [in English].

9. Samuelson, P. (1965). Proof that Properly Anticipated Prices Fluctuate Randomly. Industrial Management Review, 6, 41-49 [in English].

10. Sedláková, I. (2017). Increase in CSR among business entities in the Slovak Republic. Active, effective and transparent social services. Collection of scientific papers, Europejskie Kolegium Edukacji w Warszawie [in English].

11. Sowter, A. P., \& Gabor A., \& Granger, C. W. J. (1971). The Effect of Price on Choice: A Theoretical and Empirical Investigation. Applied Economics, 3 (3), 167-181 [in English].

12. Sucharek, P. (2016). A total image: Praise of thinking. Filozofia - Philosophy, 71 (6), 487-493 [in English].

13. Závadský, J., \& Šatanová, A., \& Hvizdová, E. (2017). Public relations management in the Internet environment. Economic Annals XXI, 165 (5-6), 124-127 [in English].

Одержано 15.03.2018 p. 